Check for updates

Cite this: RSC Adv., 2019, 9, 11202

Received 16th January 2019 Accepted 26th March 2019

DOI: 10.1039/c9ra00378a

rsc.li/rsc-advances

\section{Biosorption of anionic and cationic dyes via raw and chitosan oligosaccharide-modified Huai Flos Chrysanthemum at different temperatures $\uparrow$}

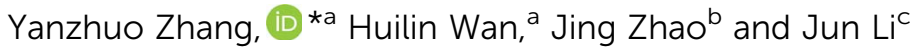

Raw Huai Flos Chrysanthemum (HFC) and modified HFC (HFC(aCO) were used for the first time as a biosorbent material to remove cationic dyes Malachite green (MG) and Crystal violet (CV), and anionic dyes Sunset yellow (SY), Lemon yellow (LY), and Carmine (CM), at different temperatures $\left(5-50{ }^{\circ} \mathrm{C}\right)$. The highest removal rates $(R)$ for dye adsorption were observed at low temperature $\left(5{ }^{\circ} \mathrm{C}\right)$ and room temperature $\left(20^{\circ} \mathrm{C}\right)$. At high $\left(500 \mathrm{mg} \mathrm{L}^{-1}\right)$ dye concentration, adsorption was completed within one minute, but the time required to reach adsorption equilibrium was longer than at the low (20 $\mathrm{mg} \mathrm{L}^{-1}$ ) concentration. The experimental data fitted very well to the Langmuir model and the values of the maximum adsorption capacity for SY, LY, CM, CV, and MG, were 481.41, 507.23, $141.78 \mathrm{mg} \mathrm{g}^{-1}, 526.32$, and $769.23 \mathrm{mg} \mathrm{L}^{-1}$, respectively. The adsorption data fit well to a pseudo-second-order kinetic model.
\end{abstract}

\section{Introduction}

Triphenylmethane dyes and azo dyes are widely used for various applications in the food, textile, paper, plastic, and rubber industries. ${ }^{\mathbf{1 - 4}}$ Sunset yellow (SY), Carmine (CM), and Lemon yellow (LY) dyes are typical azo dyes and are widely used for coloring and medicine. Malachite green (MG) and Crystal violet (CV) are triphenylmethane dyes, positive charged in aqueous solution, and used as fish fungicides and as biological dye materials. However, pollution due to wastewater containing dyes presents a serious environmental problem. The release of dye molecules into the environment leads to direct and indirect risks to aquatic and human life..$^{5-9}$ When triphenylmethane and azo dyes enter the human body, they may cause harm to the kidneys and liver, and can induce teratogenicity, carcinogenicity and mutagenicity. ${ }^{\mathbf{1 0 - 1 4}}$ Additionally, intermediate products (anilines) produced within the human body will cause further harm to human health. ${ }^{15-18}$ Diverse techniques have been applied for the removal of dye from wastewater, including physical, chemical, and biological approaches. Among these

${ }^{a}$ School of Environment, Henan Normal University, Key Laboratory for Yellow River and Huai River Water Environmental and Pollution Control, Ministry of Education, Henan Key Laboratory for Environmental Pollution Control, Xinxiang, Henan 453007, P. R. China.E-mail:83995983@qq.com;2205374076@qq.com

${ }^{b}$ School of Chemistry and Chemical Engineering, Henan Normal University, Xinxiang, Henan 453007, P. R. China. E-mail: 124236932@qq.com

'The College of Architecture and Civil Engineering, The Key Laboratory of Beijing for Water Quality Science \& Water Environment Recovery Engineering, Beijing University of Technology, Beijing 100124, China. E-mail: lijunbjut@163.com

$\uparrow$ Electronic supplementary information (ESI) available. See DOI: 10.1039/c9ra00378a methods, adsorption is superior to other methods due to its efficiency, lack of secondary pollution, and inexpensive usage. ${ }^{\mathbf{1 9}}$

There is significant interest in exploring agricultural waste as a biological material for dye removal, due to its abundance, availability, and low price. Materials that have been tested for this purpose include chitin, de-oiled soya, mangrove bark, peanut hull, modified tilapia fish scales, grapefruit peel, citric acid-esterifying wheat straw, opal dye sludge, orange peel, sulfuric acid-activated rice husk carbon, and biocomposite..$^{20-30}$

Various Chrysanthemums are cultivated in China, including Huai Flos Chrysanthemum (HFC), which has high medicinal value and can be used directly or, most commonly, used as a tea. ${ }^{31}$ The output of HFC is about 1500 tons in china each year, and about 1000 tons of HFC are discarded after use. Therefore, discarded HFC is an abundant agricultural waste, with some Chrysanthemum material recycled and used for biodiese ${ }^{32}$ and microbial fuel cells. ${ }^{33}$ Most used Chrysanthemum material is discarded or burned, which may cause environmental pollution and is a waste of biological resources. ${ }^{34,35}$ HFC contains many functional groups, such as carbonyl, carboxyl, methyl, and hydroxyl groups. Therefore, the development of HFC-based biosorbents for the removal of dyes is a promising strategy to recycle this abundant and low-cost bio-resource.

According to the results of this experiment, raw HFC shows good biosorbent adsorption of cationic dyes (CV and MG). In addition, HFC modified with chitosan oligosaccharide (HFC@CO) is an efficient biosorbent for anionic dyes (SY, LY, and $\mathrm{CM}$ ). CO has a strong affinity for protons due to its abundance of amino groups. Thus, there is strong electrostatic interaction between CO (positive charge) and anionic dyes (negative charge) that facilitate the use of CO for dye wastewater treatment. To our knowledge, most studies of biosorbent have 
described material able to adsorb only a single kind of dye (anionic or cationic), limiting its use. Additionally, there has been no report of the use of raw or modified HFC (HFC@CO) as a biosorbent to remove dyes of different charges (anionic and cationic dyes).

In this work, HFC and HFC@CO were firstly used as biosorbent material for the removal of anionic and cationic dyes under different conditions. The primary objectives of this work were to: (1) determine the optimal temperature, dosage, and dye concentrations for batch adsorption; (2) characterize the biomaterial properties of HFC and HFC@CO using Scanning Electron Microscopy (SEM), Fourier transform infrared (FTIR), Thermogravimetric Analysis (TGA), BET (Brunauer-EmmettTeller) and the Barrett-Joyner-Halenda (BJH) method; (3) analyze the fit of the data to the isothermal adsorption and adsorption kinetic models, and determine the thermodynamic parameters of the adsorption process.

\section{Materials and methods}

\subsection{Preparation of the HFC and modification with CO}

Raw HFC was obtained from Jiaozuo City, China. The HFC sample was washed several times with distilled water and ethanol to remove fly ash, dust, and other inorganic impurities. Next, the HFC was dried in an oven at $70{ }^{\circ} \mathrm{C}$ for $36 \mathrm{~h}$ until completely dry. The HFC was then crushed and screened to select powder containing particle sizes of $0.125-0.150 \mathrm{~mm}$ for batch adsorption. Finally, the obtained HFC was sealed and stored for further use or modification (ESI $\dagger$ ).

For the modification process, $4 \mathrm{~g}$ of $\mathrm{CO}$ (colloidal solution) was added to a vessel with $1000 \mathrm{~mL}$ distilled water and stirred until the CO solution was completely dissolved, producing a light-brown viscous solution. To this solution, $10 \mathrm{~g}$ HFC was added and mixed using a mechanical agitator at room temperature for $6 \mathrm{~h}$. Finally, the modified HFC material, HFC@CO, was precipitated, vacuum filtered, and dried at $70{ }^{\circ} \mathrm{C}$ for $36 \mathrm{~h}$. The color changed to deep brown after modification and after adsorption, the color changed from brown to a range of colors (ESI $\dagger$ ).

\subsection{Reagents}

Anionic and cation dyes were obtained from Aladdin Co., Ltd., China. Chitosan oligosaccharide $\left(M_{\mathrm{W}}=5000\right.$, purity $>97 \%$, powder) was purchased from Hefei Bomei Biotechnology Co., Ltd., China. The specifications of the experimental dyes are listed in Table 1.

\subsection{Adsorption experiments}

The dye adsorption tests were conducted in a conical flask containing $250 \mathrm{~mL}$ of dye solution. The mixtures were agitated in a water bath shaker at a shaking rate of $180 \mathrm{rpm}$ at different temperatures until reaching equilibrium. Each experiment was performed for $6 \mathrm{~h}$. Samples were removed at certain time intervals, centrifuged at $3200 \mathrm{rpm}$ for $2 \mathrm{~min}$, and then analyzed using a UV-765 spectrophotometer (UV-752n, Shanghai Precision and Scientific Instrument Co., Ltd). During the batch adsorption process, the $\mathrm{pH}$ of the solution was adjusted as necessary by addition of $1 \mathrm{M} \mathrm{HCl}$ or $1 \mathrm{M} \mathrm{NaOH}$.

Adsorption tests were conducted using different dosages of HFC and HFC@CO (1-5 $\left.\mathrm{g} \mathrm{L}^{-1}\right)$ for cationic dyes (CV or MG) and anionic dyes (SY, LY, or CM) in a conical flask containing $250 \mathrm{~mL}$ of the dye solution $\left(50-500 \mathrm{mg} \mathrm{L}^{-1}\right)$ at various $\mathrm{pH}$ values (2-12) and temperature $\left(5-50{ }^{\circ} \mathrm{C}\right)$. The change in dye concentration was measured at certain time intervals $(1,3,5,10,15,20$, $30,50,70$, and $90 \mathrm{~min})$.

\subsection{Data analysis}

After achievement of batch adsorption equilibrium, the adsorbing capacity and removal rate $(R)$ of dyes were calculated as follows:

$$
\begin{gathered}
q_{\mathrm{e}}=\frac{V\left(C_{0}-C_{\mathrm{e}}\right)}{M} \\
R=\frac{\left(C_{0}-C_{\mathrm{e}}\right)}{C_{0}}
\end{gathered}
$$

where, $q_{\mathrm{e}}$ is the equilibrium adsorption capacity of the adsorbent, $\mathrm{mg} \mathrm{g}^{-1} ; C_{0}$ is the initial concentration of the dye, $\mathrm{mg} \mathrm{L}^{-1} ; C_{\mathrm{e}}$ is the liquid-phase dye concentration at equilibrium, $\mathrm{mg} \mathrm{L}^{-1} ; V$ is the volume of the solution, $\mathrm{L} ; M$ is the dosage of the adsorbent, $\mathrm{g}$.

\subsection{Regeneration of HFC and HFC@CO}

The regeneration of used HFC and HFC@CO biosorbent for further dye removal was tested using batch processes. In batch desorption, the HFC and HFC@CO was exhausted by immersion of 2-3 $\mathrm{g} \mathrm{L}^{-1}$ biosorbent into the dye solution using $1 \mathrm{M}$ $\mathrm{NaOH}$ solution (for anionic dyes) or absolute ethyl alcohol (for cationic dyes) as the desorption agent for $2 \mathrm{~h}$. The desorption conditions were identical to those used for adsorption. The regeneration of HFC and HFC@CO was evaluated over four successive regeneration cycles.

Table 1 The quality of dyes used in this work

\begin{tabular}{lllll}
\hline Name & Characteristics & Molecular weight & Wavelength & Molecular formula \\
\hline Crystal violet, CV & Cationic dye & 407.98 & 580 & $\mathrm{C}_{25} \mathrm{H}_{30} \mathrm{~N}_{3} \mathrm{Cl} \cdot 9 \mathrm{H}_{2} \mathrm{O}$ \\
Malachite green, MG & Cationic dye & 364.92 & 617 & $\mathrm{C}_{23} \mathrm{H}_{25} \mathrm{CIN}_{2}$ \\
Sunset yellow, SY & Anionic dye & 452.37 & 482 & $\mathrm{C}_{16} \mathrm{H}_{10} \mathrm{~N}_{2} \mathrm{Na}_{2} \mathrm{O}_{7} \mathrm{~S}_{2}$ \\
Lemon yellow, LY & Anionic dye & 534.36 & 426 & $\mathrm{C}_{16} \mathrm{H}_{9} \mathrm{~N}_{4} \mathrm{O}_{9} \mathrm{~S}_{2} \mathrm{Na}_{3}$ \\
Carmine, CM & Anionic dye & 604.47 & 506 & $\mathrm{C}_{20} \mathrm{H}_{11} \mathrm{~N}_{2} \mathrm{Na}_{3} \mathrm{O}_{10} \mathrm{~S}_{3}$
\end{tabular}




\section{Results and discussion}

\subsection{Characteristics of biosorbent}

3.1.1 SEM analysis. The morphological structures of HFC and HFC@CO were characterized by SEM (Quanta 200, FEI, USA). HFC was composed of volatile oils, stevia, and saccharides. The data shows that the raw HFC has high porosity (ESI $\dagger$ ). After loading with CO, the surface of the HFC became smoother as it was filled with CO during the modification process, but its porous morphology remained. The loaded CO and numerous tiny pores facilitated dye collection and adsorption.

3.1.2 FTIR analysis. FT-IR was performed on an Alpha Infrared Spectrometer (Bruker, Germany). The main spectral peaks of functional groups were observed at 3358, 2928, 1733, $1646,1383,1158,1243,1048,861$, and $756 \mathrm{~cm}^{-1}$ in raw HFC (ESI $\dagger$ ). The distinct band at $3358 \mathrm{~cm}^{-1}$ may indicate the $\mathrm{O}-\mathrm{H}$ stretching vibration of stevia and saccharides. The distinct band at $2928 \mathrm{~cm}^{-1}$ was attributed to the stretch vibration of $\mathrm{C}-\mathrm{H}$ bond and the bond at $1383 \mathrm{~cm}^{-1}$ was assigned to $\mathrm{C}-\mathrm{H}$ bending vibrations in the methyl and methylene groups. The peak at $1733 \mathrm{~cm}^{-1}$ was assigned to $\mathrm{C}=\mathrm{O}$ stretching vibrations. The strong band at $1646 \mathrm{~cm}^{-1}$ was ascribed to $\mathrm{N}-\mathrm{H}$ bend vibrations. The peak at $1158 \mathrm{~cm}^{-1}$ was attributed to $\mathrm{C}-\mathrm{O}$ stretching vibration, indicating the presence of carboxyl groups on the HFC. The peak at $1243 \mathrm{~cm}^{-1}$ and a weak band at around $1048 \mathrm{~cm}^{-1}$ may be due to $\mathrm{C}-\mathrm{O}$ stretching vibrations in alcohols, phenols, or ether groups. There was no change after adsorption of CV and MG by raw HFC.

There was no obvious change after modification other than a slight change in the position of the main spectral peaks in the modified HFC@CO (ESI $\dagger$ ). The new band at $2356 \mathrm{~cm}^{-1}$ may represent the amino group $\left(-\mathrm{NH}_{2}\right)$, indicating the successful loading of amino groups on the surface of HFC@CO. The new band at around $1459 \mathrm{~cm}^{-1}$ may be attributed to $\mathrm{C}-\mathrm{H}$ bending vibrations in methyl and methylene groups. The $1408 \mathrm{~cm}^{-1}$ band may be due to $\mathrm{C}=\mathrm{C}$ skeletal vibrations. Additionally, the
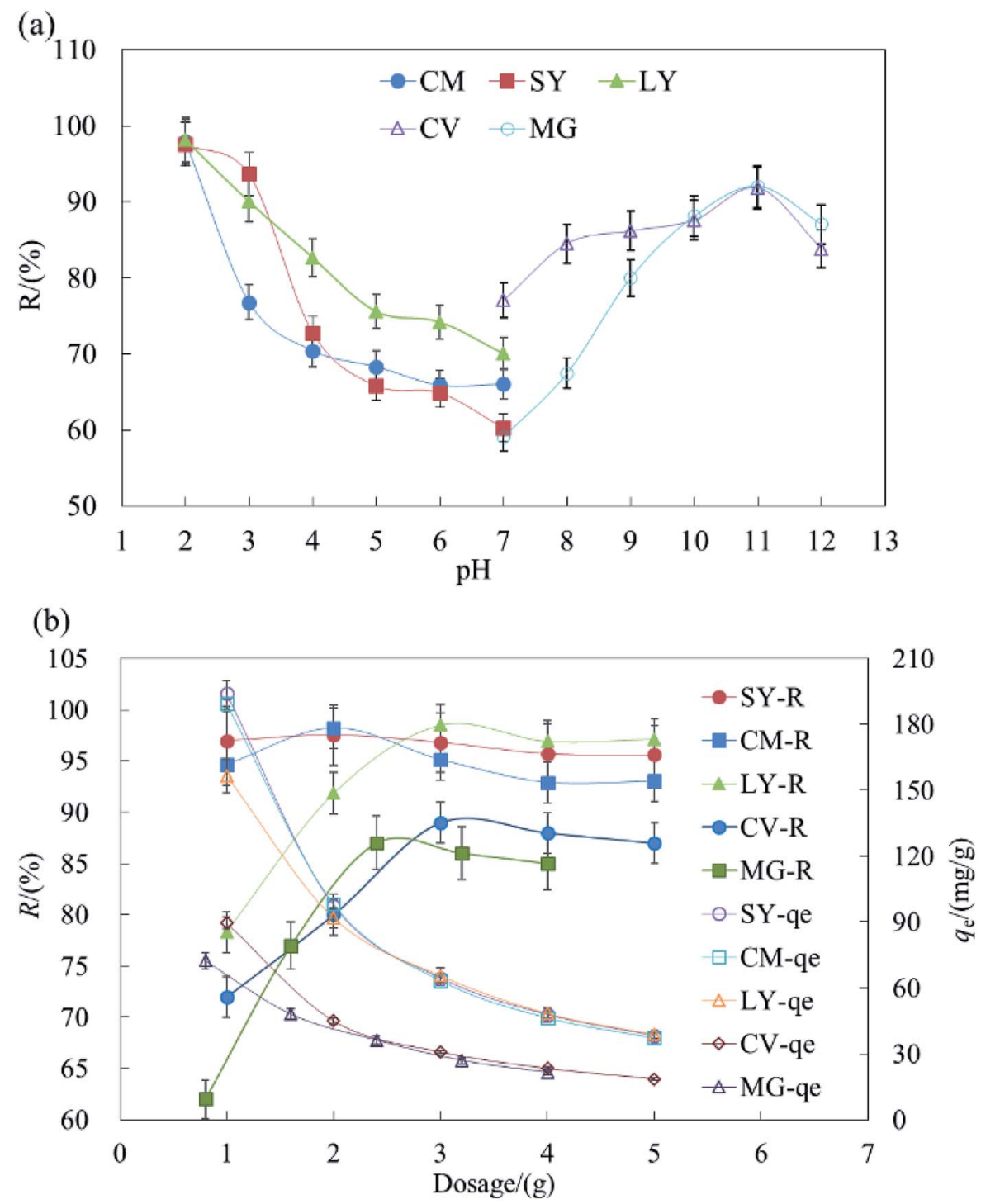

Fig. 1 The effect of $\mathrm{pH}$ and dosage on the removal of dyes by HFC and HFC@CO. 
strong peak of HFC@CO at1079 $\mathrm{cm}^{-1} \mathrm{C}-\mathrm{O}-\mathrm{C}$ band at around $1026 \mathrm{~cm}^{-1}$ confirmed the presence of saccharides. The data shows the FTIR spectra of the modified HFC@CO after the adsorption of dyes (ESI $\dagger$ ). The peak at $1727 \mathrm{~cm}^{-1}$ disappeared after dye adsorption, suggesting $\mathrm{CO}$ occupied the active sites of the HFC@CO. In addition, a new peak of HFC@CO at $1523 \mathrm{~cm}^{-1}$ after adsorption indicated the presence of aromatic heterocyclic material in the azo dyes, demonstrating the adsorption of dyes on HFC@CO.

3.1.3 BET and BJH analysis. The $\mathrm{N}_{2}$ adsorption-desorption isotherm values for HFC and HFC@CO were analyzed (ESI†). The obtained $\mathrm{N}_{2}$ adsorption isotherm values are similar to that of the type IV isotherm (in IUPAC classification). ${ }^{36}$ This pattern is consistent with a multi-layer reversible process describing the interaction between biosorbent and dyes. The substitution of the measured values into the BET equation allowed the determination of a calculated surface area for HFC and HFC@CO of 47.67 and $40.17 \mathrm{~m}^{2} \mathrm{~g}^{-1}$, respectively (ESI $\dagger$ ). The total pore volume and average pore diameters were $0.4919 \mathrm{~cm}^{3} \mathrm{~g}^{-1}$ and $21.63 \mathrm{~nm}$ for HFC and $0.4398 \mathrm{~cm}^{3} \mathrm{~g}^{-1}$ and $18.61 \mathrm{~nm}$ for HFC@CO, respectively. Although the specific surface area decreased, different properties of dyes can adsorbed by HFC@CO and amplify the scope of its use after modification.

3.1.4 TG analysis. The chitosan oligosaccharide-modified Huai Flos Chrysanthemum was further measured by TGA under air condition. The weight loss curves for raw HFC and
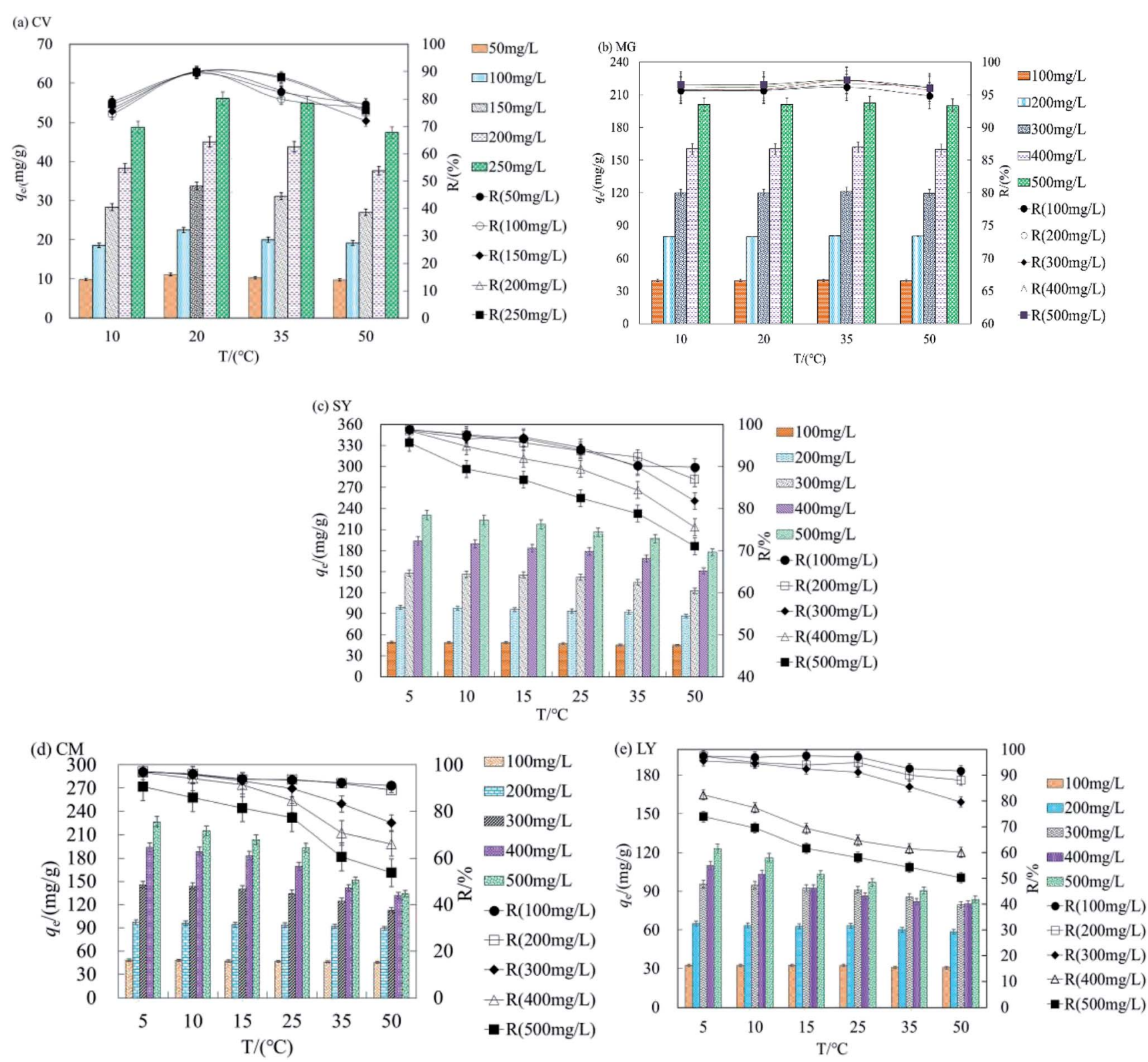

Fig. 2 The batch adsorption data under different concentration for (a) CV, (b) MG (c) SY, (d) CM (e) LY $\left(C_{0}=50-250 \mathrm{mg} \mathrm{L}{ }^{-1}, \mathrm{pH}=11, \mathrm{dosage}=\right.$ $2.4 \mathrm{~g} \mathrm{~L}^{-1}$ or $3 \mathrm{~g} \mathrm{~L}^{-1} ; n=3$, error $< \pm 3 \%$ for cationic dyes by HFC); $\left(C_{0}=100-500 \mathrm{mg} \mathrm{L}^{-1}, \mathrm{pH}=2\right.$, dosage $=2 \mathrm{~g} \mathrm{~L}^{-1}$ or $3 \mathrm{~g} \mathrm{~L}^{-1}$; $n=3$, error $< \pm 3 \%$ for anionic dyes by HFC(aCO). 
HFC@CO were analyzed. The thermal stability was divided into three stages (ESI $\dagger$ ). First, for HFC and HFC@CO, the weight loss between 20 and $230{ }^{\circ} \mathrm{C}$ was due to the release of free water and the structural water of biosorbents. Next, between 230 and 500$550{ }^{\circ} \mathrm{C}$, oxygenolysis of the carbonaceous material occurred under air. Then, the weight loss remained stable above $550{ }^{\circ} \mathrm{C}$ due to the disappearance of carbon substances. For the overall TGA process, the proportion of weight loss was $90 \%$ and $95 \%$ for the HFC@CO and HFC, respectively. Overall, the results indicate the successful modification of $\mathrm{HFC}$ by chitosan oligosaccharide.

\subsection{Parameters affecting dye adsorption}

3.2.1 Effect of $\mathbf{p H}$ and dosage. The surface charge of HFC@CO and the ionization degree of the dyes were strongly affected by the solution pH. Fig. 1a shows the effect of $\mathrm{pH}$ on the removal of anionic and cationic dyes. The removal rate $(R)$ reached the maximum value at $\mathrm{pH} 2.0$ and $\mathrm{pH} 11.0$ for the anionic and cationic dyes, respectively.

The results indicated that acidic conditions are suitable for the adsorption of anionic dyes but basic conditions are more suitable for cationic dyes. During the removal of dyestuff via adsorption, $\mathrm{pH}$ can affect the solubility and site dissociation of the biosorbent in solution, the superficial electrification condition of dyes, and the de-coloration effect of HFC and HFC@CO. The effect of the solution $\mathrm{pH}$ on dye uptake could also be explained based on the different zero charge point $\left(P_{\mathrm{zcp}}\right)$ values of HFC and HFC@CO. Their $P_{\text {zcp }}$ were 3.1 and 9.0, so at a higher $\mathrm{pH}$, the surface of the HFC particles become negatively charged, facilitating the adsorption of cationic dyes. In contrast, at a lower pH, the surface of the HFC@CO particles may become positively charged $\left(P_{\mathrm{zcp}}=9.0\right)$, allowing greater electrostatic attraction to negatively charged dye anions.

Fig. 1b shows maximum removal rates $(R)$ of $2 \mathrm{~g} \mathrm{~L}^{-1}, 3 \mathrm{~g} \mathrm{~L}^{-1}$, $3 \mathrm{~g} \mathrm{~L}^{-1}, 3 \mathrm{~g} \mathrm{~L}^{-1}$, and $2.4 \mathrm{~g} \mathrm{~L}^{-1}$ for $\mathrm{SY}, \mathrm{CM}, \mathrm{LY}, \mathrm{CV}$, and MG in batch adsorption. Increased dosage can improve the removal rate, but will reduce the equilibrium adsorption capacity $\left(q_{\mathrm{e}}\right)$. This may be because increased HFC@CO provides more sites for the adsorption of dyestuffs, and thus increases the removal rate. On the other hand, when the initial dye concentration is kept constant and the removal rate improves, there are fewer dye molecules on the biosorbent. Then, when the quantity of biosorbent increases, the relative adsorption rate is reduced and the dye adsorption capacity decreases with increased biosorbent. Therefore, this trade-off should be considered when determining the appropriate amount of adsorbent.

3.2.2 Effect of temperature. This work shows that temperature is a critical factor for the adsorption process. Fig. 2a-e shows the relationship between $q_{\mathrm{e}}$ and $T$ for different initial concentrations of cationic and anionic dyes.

As shown in Fig. 2a, $q_{\mathrm{e}}$ and $R$ were highest for adsorption of $\mathrm{CV}$ by $\mathrm{HFC}$ at $20{ }^{\circ} \mathrm{C}$. The max difference value ( $D$-value) of $q_{\mathrm{e}}$ between 10 and $50{ }^{\circ} \mathrm{C}$ was $5.66-34.68 \mathrm{mg} \mathrm{L}^{-1}$ at concentrations of 50-250 $\mathrm{mg} \mathrm{L}^{-1}$. The $D$-value of $q_{\mathrm{e}}$ increased gradually as the concentration of dyes increased and the average $R$ difference was $14.12 \%$ for CV. Fig. 2 b shows $q_{\mathrm{e}}$ and $R$ remained constant for adsorption of $\mathrm{MG}$ by $\mathrm{HFC}$ at $10-50{ }^{\circ} \mathrm{C}$, and the optimum temperature range was $20-35^{\circ} \mathrm{C}$. Therefore, there is a very small difference of $q_{\mathrm{e}}$ and $R$ at different temperatures. Clearly, cationic dyes were adsorbed efficiently at room temperature by raw HFC.

The optimal temperature for adsorption of anionic dyes by HFC@CO differed from that seen for the raw material. Fig. 2c-e show that as temperature increased, $q_{\mathrm{e}}$ and $R$ decreased at all initial concentrations. The $q_{\mathrm{e}}$ and $R$ decreased less at lower concentrations (100-300 $\mathrm{mg} \mathrm{L}^{-1}$ ), suggesting that temperature did not significantly affect adsorption capacity at lower concentrations. However, the $D$-value of $q_{\mathrm{e}}$ increased at concentrations of $400-500 \mathrm{mg} \mathrm{L}^{-1}$. The $\max D$-values were 20.2, 13.4 , and $17.9 \mathrm{mg} \mathrm{L}^{-1}$ and the difference of removal rate $(D-R)$ was $8.78,12.06$, and $7.16 \%$ for SY, LY, and CM, respectively, for an initial concentration of $500 \mathrm{mg} \mathrm{\textrm {L } ^ { - 1 }}$ at $5-15^{\circ} \mathrm{C}$. Additionally, when the temperature reached the reported optimal range (20$50{ }^{\circ} \mathrm{C}$ ), the $D$-value and $D-R$ increased. The data presented in Fig. 2c-e also show that $q_{\mathrm{e}}$ was reduced by $52.9,39.3$, and $87.3 \mathrm{mg} \mathrm{L}^{-1}$ and $R$ decreased by $21.59,23.58$, and $34.9 \%$ for $\mathrm{SY}$, LY, and CM, respectively, at an initial concentration of

Table 2 Isotherm parameters for dyes adsorption on HFC and $\mathrm{HFCaCO}^{a}$

\begin{tabular}{lll}
\hline Dyes & Parameters & Batch a \\
\hline \multirow{2}{*}{ Langmuir, the whole concentration range } & $\left(100-500 \mathrm{mg} \mathrm{L}^{-1}\right)$ \\
SY & $q_{\mathrm{m}}\left(\mathrm{mg} \mathrm{g}^{-1}\right)$ & 481.41 \\
& $b\left(\mathrm{~L} \mathrm{mg}^{-1}\right)$ & 10.21 \\
& $R^{2}$ & 0.9840 \\
$\mathrm{CM}$ & $q_{\mathrm{m}}\left(\mathrm{mg} \mathrm{g}^{-1}\right)$ & 507.23 \\
& $b\left(\mathrm{~L} \mathrm{mg}^{-1}\right)$ & 19.05 \\
& $R^{2}$ & 0.9625 \\
$\mathrm{LY}$ & $q_{\mathrm{m}}\left(\mathrm{mg} \mathrm{g}^{-1}\right)$ & 141.78 \\
& $b\left(\mathrm{~L} \mathrm{mg}^{-1}\right)$ & 6.24 \\
& $R^{2}$ & 0.9821 \\
$\mathrm{CV}$ & $q_{\mathrm{m}}\left(\mathrm{mg} \mathrm{g}^{-1}\right)$ & 526.32 \\
& $b\left(\mathrm{~L} \mathrm{mg}^{-1}\right)$ & 0.0039 \\
& $R^{2}$ & 0.9997 \\
$\mathrm{MG}$ & $q_{\mathrm{m}}\left(\mathrm{mg} \mathrm{g}^{-1}\right)$ & 769.23 \\
& $b\left(\mathrm{~L} \mathrm{mg}^{-1}\right)$ & 0.011 \\
& $R^{2}$ & 0.9982
\end{tabular}

Freundlich, the whole concentration range (100-500 $\left.\mathrm{mg} \mathrm{L}^{-1}\right)$ $\mathrm{SY} \quad K_{\mathrm{F}}\left(\mathrm{mg} \mathrm{g}^{-1}\right)\left(\mathrm{L} \mathrm{mg}^{-1}\right)^{1 / n} \quad 38.11$ $n^{-1} \quad 0.0083$ $R^{2}\left(\mathrm{mg} \mathrm{g}^{-1}\right)\left(\mathrm{Lg}^{-1}\right)^{1 / n} \quad 0.9532$

$\mathrm{CM} \quad K_{\mathrm{F}}\left(\mathrm{mg} \mathrm{g}^{-1}\right)\left(\mathrm{L} \mathrm{mg}^{-1}\right)^{1 / n} \quad 51.72$

$n^{-1} \quad 0.4229$

$K_{\mathrm{F}}\left(\mathrm{mg} \mathrm{g}^{-1}\right)\left(\mathrm{L} \mathrm{mg}^{-1}\right)^{1 / n} \quad 35.18$ $n^{-1} \quad 0.2803$ $R^{2} \quad 0.8390$ $\mathrm{CV} \quad K_{\mathrm{F}}\left(\mathrm{mg} \mathrm{g}^{-1}\right)\left(\mathrm{L} \mathrm{mg}^{-1}\right)^{1 / n} \quad 1.99$ $n^{-1} \quad 0.9860$ $R^{2} \quad 0.9994$ MG $\quad K_{\mathrm{F}}\left(\mathrm{mg} \mathrm{g}^{-1}\right)\left(\mathrm{L} \mathrm{mg}^{-1}\right)^{1 / n} \quad 7.29$ $n^{-1}+1.142$

0.9920

${ }^{a} T=20^{\circ} \mathrm{C}$, pH 11.0, dosage $=2.4$ and $3 \mathrm{~g} \mathrm{~L}^{-1}$ for $\mathrm{CV}$ and $\mathrm{MG} ; T=5{ }^{\circ} \mathrm{C}$, dosage $=2 \mathrm{~g} \mathrm{~L}^{-1}$ or $3 \mathrm{~g} \mathrm{~L}^{-1}$ and $\mathrm{pH} 2.0$ for anionic dyes. 
$500 \mathrm{mg} \mathrm{L}{ }^{-1}$, when the temperature changed from 5 to $50{ }^{\circ} \mathrm{C}$. Overall, these data show that the adsorption process may be exothermic, and the physical binding force between dyestuff molecules and the functional groups (the amino groups) of the biosorbent decreased as the temperature increased.

The cationic dyes (raw HFC) and anionic dyes (HFC@CO) can be adsorbed efficiently at room temperature $\left(20^{\circ} \mathrm{C}\right)$ and low temperature $\left(5-10^{\circ} \mathrm{C}\right)$. Thus, HFC and HFC@CO can be used under a wide range of temperatures for the adsorption of cationic and anionic dyes.

3.2.3 Effect of low and high concentration. The data in Fig. 3a and b show the effect of high and low dye concentrations for different contact times using HFC and HFC@CO. As shown in Fig. 3a, the $R$ value increased significantly at 1-30 min for high concentration. The $D-R$ was 20.02 to $34.48 \%$ between 1-
$30 \mathrm{~min}$, and after saturation of the biosorbent, the value of $R$ remained constant after $50 \mathrm{~min}$.

The data in Fig. 3b show that the overall change trend was the same at low and high concentrations. The adsorption equilibrium time at low concentration is slightly different from high concentration, with a time point of $30 \mathrm{~min}$. The $D-R$ was in the range of 37.39 to $59.62 \mathrm{mg} \mathrm{L}^{-1}$ within $20 \mathrm{~min}$. Comparison of the data in Fig. 3a and b shows that the upward slope of $D-R$ was bigger at high concentration. This phenomenon means that when the dye concentration is higher, the adsorption equilibrium time will increase accordingly. However, the difference in slope is mainly due to the adsorption rate, because at high concentration, the adsorption rate is very fast due to osmotic pressure, allowing the dye molecules to be highly adsorbed on the biosorbent faster than $1 \mathrm{~min}$. Therefore, the slope of $D-R$ at

(a) high concentration- 250 or $500 \mathrm{mg} / \mathrm{L}$

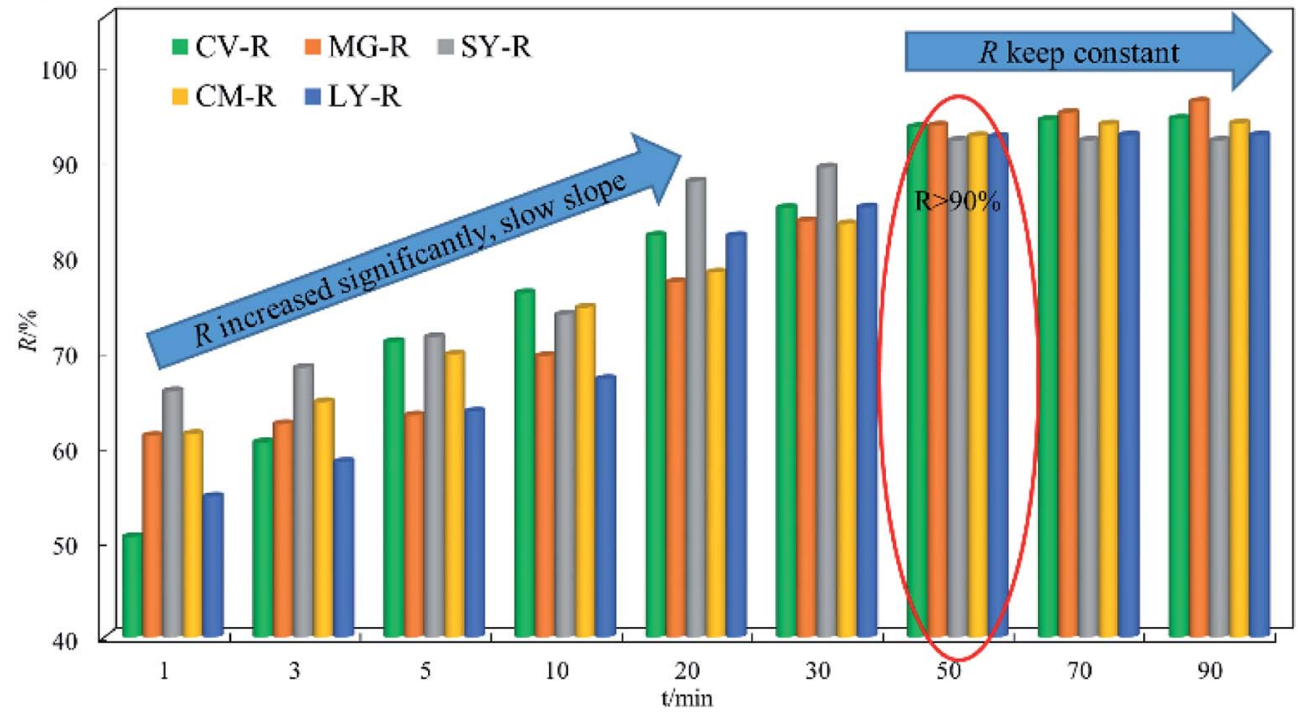

(b) low concentration- $20 \mathrm{mg} / \mathrm{L}$

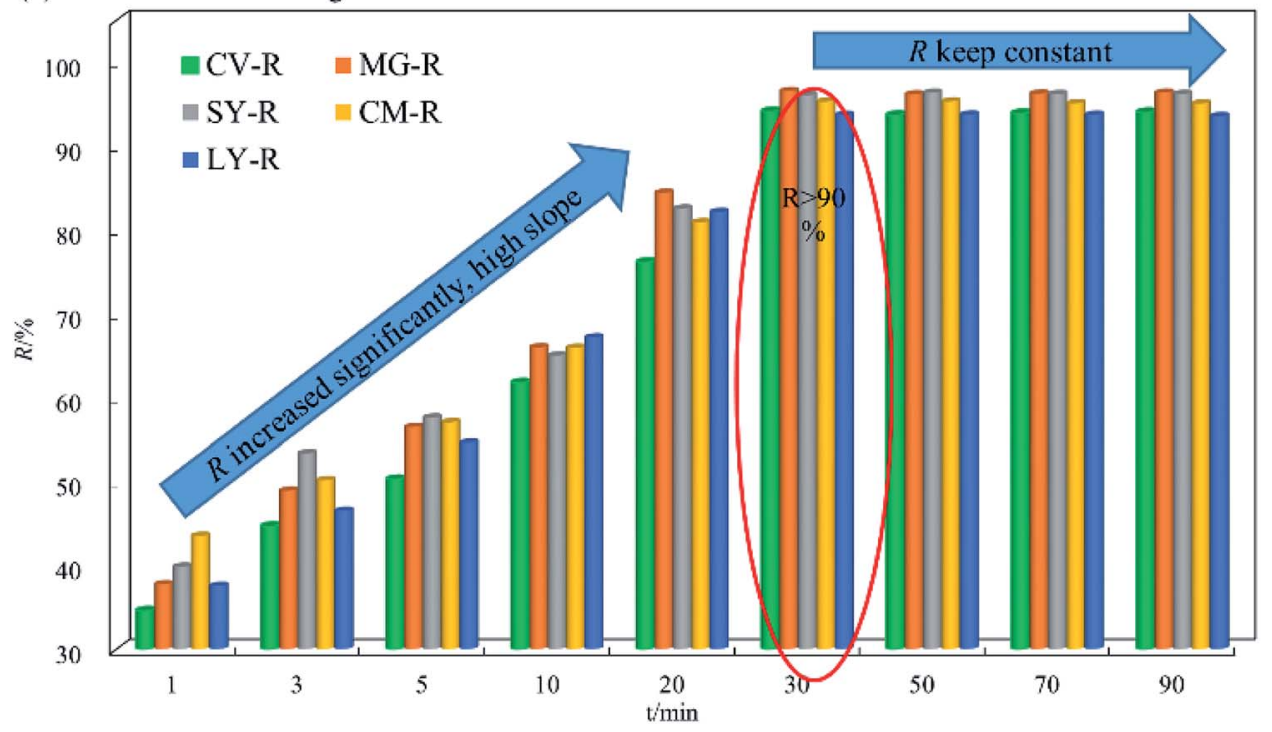

Fig. 3 The batch adsorption data under different concentration for SY, CM, LY, CV and MG (high $C_{0}=250$ and $500 \mathrm{mg} \mathrm{L}^{-1}$, low $C_{0}=20 \mathrm{mg} \mathrm{L}^{-1}$, $\mathrm{pH}=11$, dosage $=2.4 \mathrm{~g} \mathrm{~L}^{-1}$ or $3 \mathrm{~g} \mathrm{~L}^{-1} ; n=3$, error $< \pm 3 \%$ for cationic dyes by HFC); (high $C_{0}=500 \mathrm{mg} \mathrm{L}^{-1}$, low $C_{0}=20 \mathrm{mg} \mathrm{L}^{-1} \mathrm{pH}^{-1}=2$, dosage $=2 \mathrm{~g} \mathrm{~L}^{-1}$ or $3 \mathrm{~g} \mathrm{~L}^{-1} ; n=3$, error $< \pm 3 \%$ for anionic dyes by HFC(aCO). 
high concentrations is smaller than that at low concentration. It is important to note that the low slope does not indicate a low adsorption rate, and that the initial adsorption capacity for high concentration is actually higher than at low concentration. Overall, HFC and HFC@CO exhibit excellent adsorption of dyes at high and low concentrations.

\subsection{Biosorption isotherms}

An adsorption isotherm describes how adsorption molecules reach the equilibrium state during the adsorbing process of both liquid- and solid-phases. The adsorption equilibrium equations used here are shown in the ESI $\dagger$.

The parameter values related to Langmuir and Freundlich models are listed in Table 2 . As indicated by the $R^{2}$ values, dye adsorption by HFC and HFC@CO does not fit well to the Freundlich model. Using the Langmuir model, the data shows the highest adsorption capacity with mean $R^{2}$ values of 0.9903 , 0.9831 , and 0.9984 for SY, CM, and LY, respectively, at low temperature $\left(5^{\circ} \mathrm{C}\right)$. For $\mathrm{CV}$ and $\mathrm{MG}$, the mean $R^{2}$ values were 0.9997 and 0.9982 at room temperature $\left(20{ }^{\circ} \mathrm{C}\right)$. The $q_{\mathrm{m}}$ values were $481.41,507.23,141.78,526.32$, and $769.23 \mathrm{mg} \mathrm{L}^{-1}$ for SY, $\mathrm{CM}, \mathrm{LY}, \mathrm{CV}$, and $\mathrm{MG}$, respectively, at 5 or $20^{\circ} \mathrm{C}$. Overall, the results indicated that the Langmuir model was best qualified to describe the experimental data and that HFC materials showed effective adsorption of dyes, both before and after modification. This suggests that the adsorption process mainly depends on electrostatic attraction and special functional sites, and there was monolayer adsorption onto the HFC and HFC@CO surface.

Table 3 compared the maximum adsorption capacity of HFC and HFC@CO with that of with other adsorbents, including some biosorbent materials. Compared with other reported biosorbent material, HFC and HFC@CO showed better adsorption of cationic and anionic dyes. In particular, cationic dyes were efficiently adsorbed onto raw HFC.

\subsection{Biosorption kinetics}

Kinetic models are used to describe the adsorption process and explain the control principles from the perspective of kinetics. According to adsorption kinetics equations (ESI $\dagger$ ), we tested pseudo-first order and pseudo-second order kinetic models ${ }^{37,38}$ for their fit to the data as a way to study the reaction pathway and rate-controlling step of the adsorption of cationic and anionic dyes by HFC and HFC@CO.

The fitted parameters are shown in Table 4. We found that the $q_{\mathrm{e}, \mathrm{cal}}$ values were all lower than $q_{\mathrm{e} \text {,exp }}$, and the $R^{2}$ values were between $0.7007-0.9899$, indicating a poor fit of the experimental data to the pseudo-first-order kinetic model. This poor fit suggests that this model cannot fully describe the complete adsorbing process, but may describe the primary stage of adsorption. $^{39,40}$

The calculated $R^{2}$ values were closer to 1.000 for the pseudosecond-order kinetic model than for the pseudo-first-order kinetic model. Additionally, the $q_{\mathrm{e}, \mathrm{cal}}$ showed good agreement

Table 3 Adsorption capacity of cationic and anionic dyes by other adsorbents

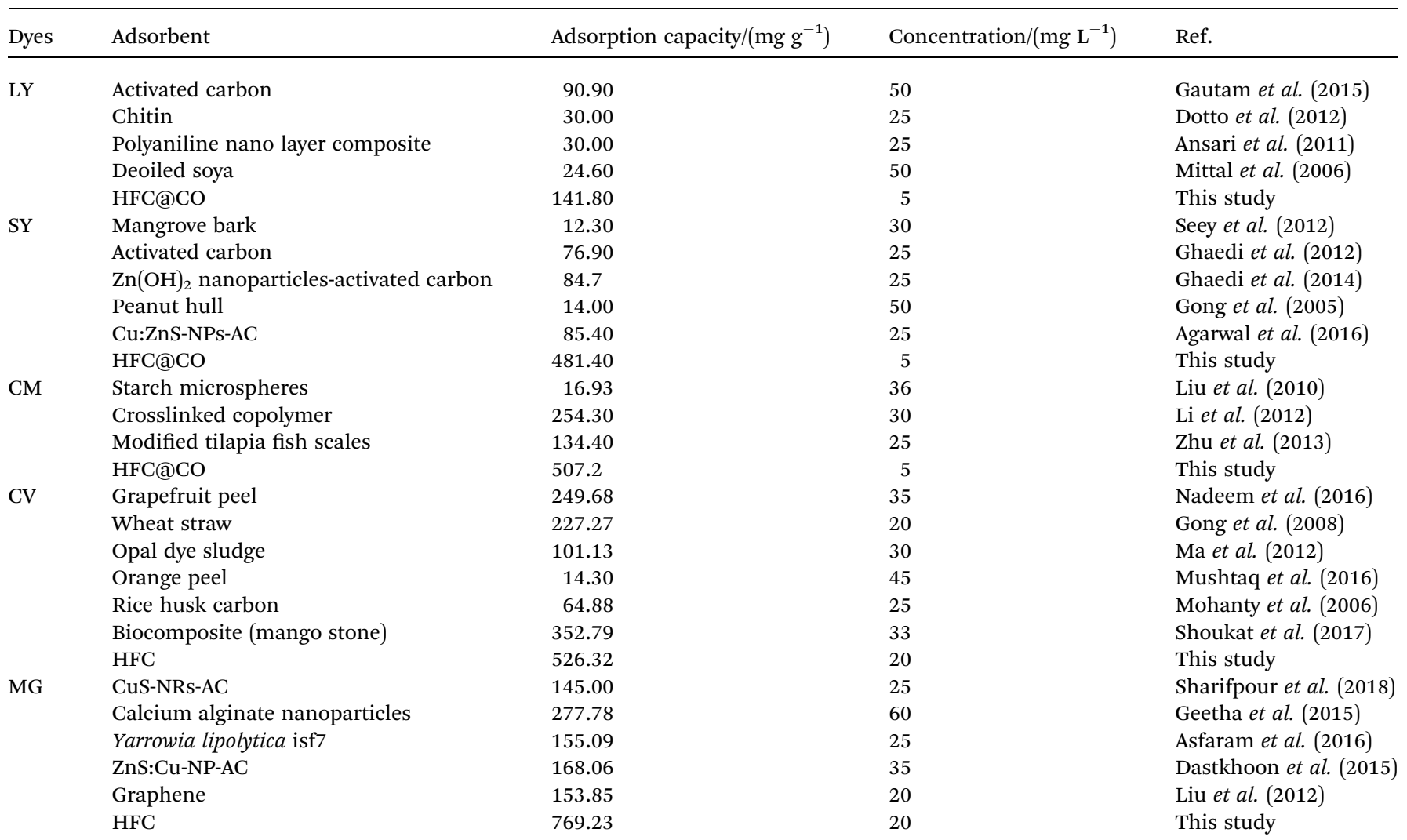


Table 4 Kinetic model parameters for adsorption of anionic dyes by HFCaCO at different initial concentration ${ }^{a}$

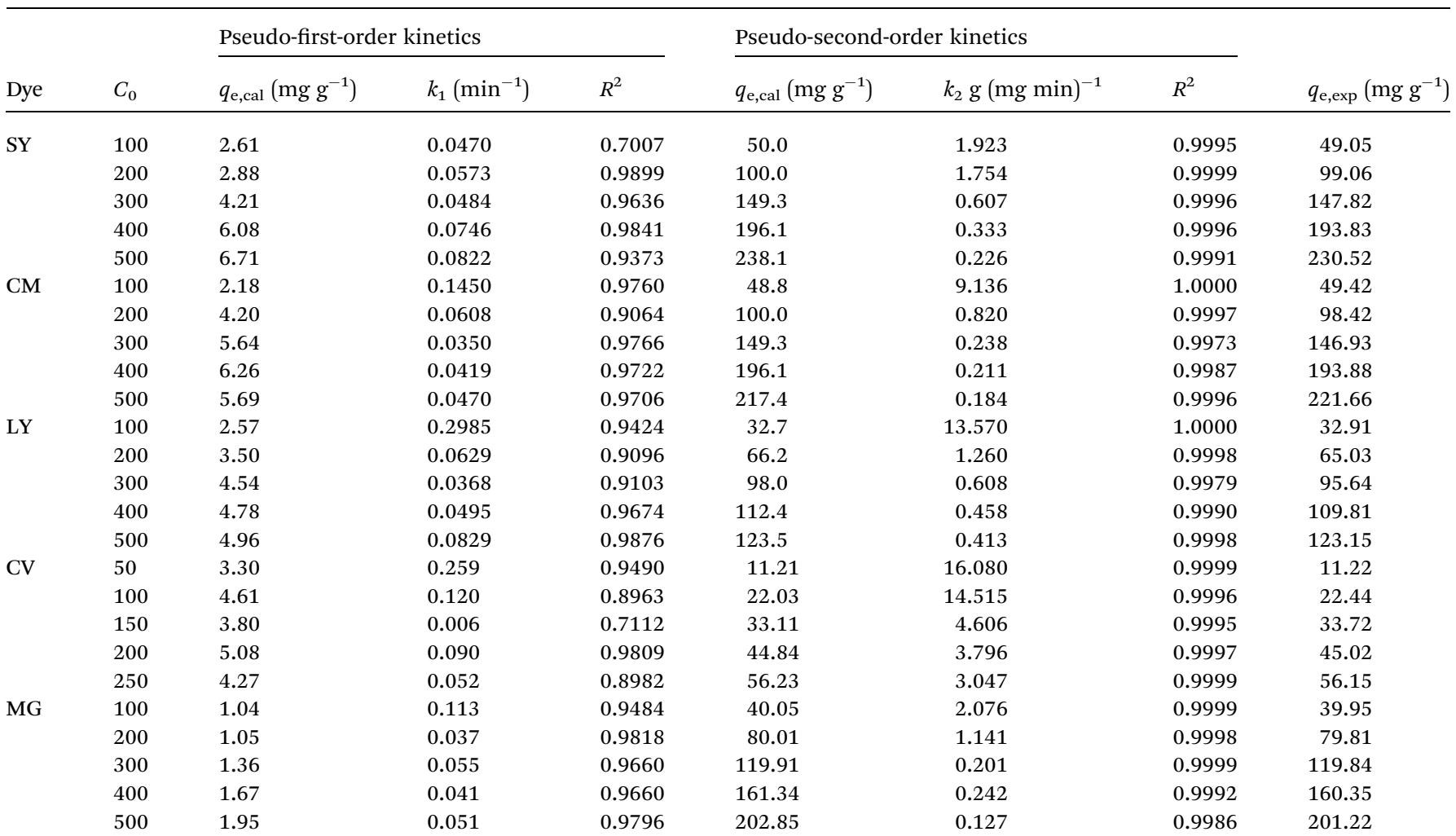

${ }^{a} T=20{ }^{\circ} \mathrm{C}$, pH 11, dosage $=2.4$ and $3.0 \mathrm{~g} \mathrm{~L}^{-1}$ for $\mathrm{CV}$ and MG; $T=5{ }^{\circ} \mathrm{C}$, dosage $=2 \mathrm{~g} \mathrm{~L}^{-1}$ or $3 \mathrm{~g} \mathrm{~L}^{-1}$ and $\mathrm{pH} 2.0$ for anionic dyes.

with the $q_{\mathrm{e}}$ and the $R^{2}$ values, indicating high correlation. Overall, the pseudo-second-order kinetic model better fit the experimental data.

\subsection{Adsorption thermodynamics HFC@CO}

Thermodynamic parameters include the Gibbs free energy $\left(\Delta G^{0}\right)$, the enthalpy change $\left(\Delta H^{0}\right)$, and the entropy change $\left(\Delta S^{0}\right)$.

$$
\begin{gathered}
\Delta G^{0}=-R T K_{\mathrm{d}} \\
\ln K_{\mathrm{d}}=\frac{\Delta S^{0}}{R}-\frac{T \Delta H^{0}}{R T} \\
K_{\mathrm{d}}=\frac{q_{\mathrm{e}}}{C_{\mathrm{e}}} \\
\Delta G^{0}=\Delta H^{0}-T \Delta S^{0}
\end{gathered}
$$

where $R$ is the universal gas constant $\left(8.314 \mathrm{~J}(\mathrm{~mol} \mathrm{~K})^{-1}\right), T$ is the temperature $(K)$, and $K_{\mathrm{d}}$ is the thermodynamic equilibrium constant.

The data presented in Table 5 show negative values of $\Delta G^{0}$ and $\Delta H^{0}$, indicating that the adsorption of anionic dyes is likely a spontaneous exothermic process. Differently, the data presented in Table 6 show a positive value of $\Delta H^{0}$, indicating a spontaneous endothermic process for the adsorption of cationic dyes. These results were consistent with previous conclusions (Section 3.2.1), which showed that $q_{\mathrm{e}}$ decreased with increased temperature for anionic dyes and increased with increased temperature $i$ for cationic dyes. In conclusion, the adsorption of anionic dyes by HFC@CO is a spontaneous exothermic process and the adsorption of cationic dyes by HFC is a spontaneous endothermic process.

Table 5 Thermodynamic parameters for adsorption of anionic dyes by $\mathrm{HFCACO}^{a}$

\begin{tabular}{llllll}
\hline & & & \multicolumn{4}{c}{$\Delta G^{0}\left(\mathrm{~kJ} \mathrm{~mol}^{-1}\right)$} \\
\cline { 3 - 6 } Dye & $\Delta H^{0}\left(\mathrm{~kJ} \mathrm{~mol}^{-1}\right)$ & $\Delta S^{0}\left(\mathrm{~J} \mathrm{~mol}^{-1} \mathrm{~K}^{-1}\right)$ & $278 \mathrm{~K}$ & $283 \mathrm{~K}$ & $288 \mathrm{~K}$ \\
\hline SY & -62.41 & -199.43 & -8.05 & -6.81 & -6.06 \\
CM & -84.96 & -282.97 & -7.84 & -6.02 & -5.02 \\
LY & -39.78 & -121.34 & -6.04 & -5.48 & -4.82
\end{tabular}

${ }^{a} C_{\text {anionic dye }}=100,200,300,400$ and $500 \mathrm{mg} \mathrm{L}^{-1}$, HFC@CO dosage $=$ $2 \mathrm{~g} \mathrm{~L}^{-1}, 3 \mathrm{~g} \mathrm{~L}^{-1}, 2 \mathrm{~g} \mathrm{~L}^{-1}$ and $\mathrm{pH} 2.0$ for SY, LY, CM.

Table 6 Thermodynamic parameters for adsorption of cationic dyes by $\mathrm{HFC}^{a}$

\begin{tabular}{llllll}
\hline & & & \multicolumn{3}{c}{$\Delta G^{0}\left(\mathrm{~kJ} \mathrm{~mol}^{-1}\right)$} \\
\cline { 4 - 6 } Dye & $\Delta H^{0}\left(\mathrm{~kJ} \mathrm{~mol}^{-1}\right)$ & $\Delta S^{0}\left(\mathrm{~J} \mathrm{~mol}^{-1} \mathrm{~K}^{-1}\right)$ & $293 \mathrm{~K}$ & $308 \mathrm{~K}$ & $323 \mathrm{~K}$ \\
\hline CV & 20.73 & 72.25 & -0.37 & -1.28 & -2.57 \\
MG & 8.12 & -6.47 & -6.31 & -6.03 & -6.08
\end{tabular}

${ }^{a} \mathrm{pH} \mathrm{7,} C_{\mathrm{MG}}=100,200,300,400$ and $500 \mathrm{mg} \mathrm{L}^{-1}$ and HFC dosage $=$ $2.4 \mathrm{~g} \mathrm{~L}^{-1}$ for MG; pH 11, CV $=50,100,150,200$ and $250 \mathrm{mg} \mathrm{L}^{-1}$ and $\mathrm{HFC}$ dosage $=3 \mathrm{~g} \mathrm{~L}^{-1}$ for $\mathrm{CV}$. 


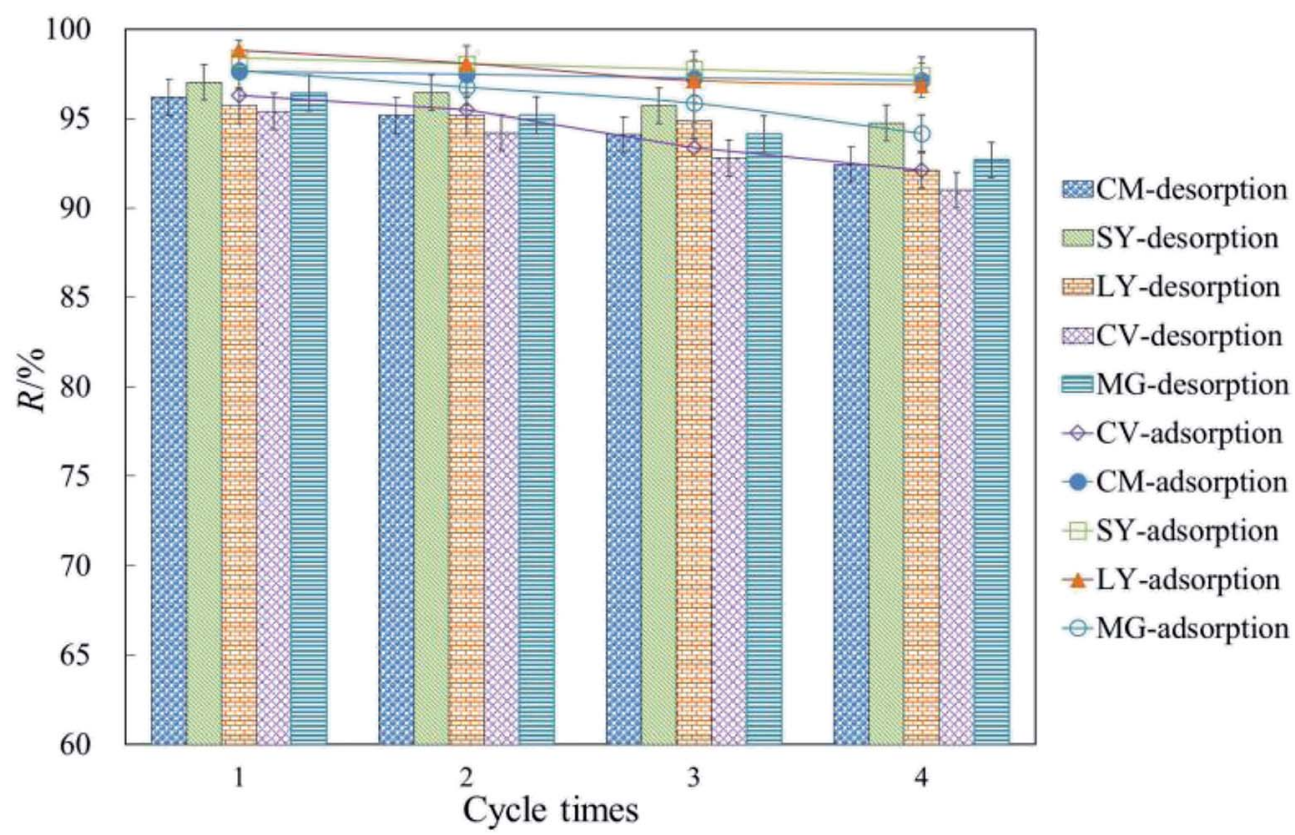

Fig. 4 Regeneration of dyes from HFC and HFC (aCO for four adsorption-desorption cycles $\left(T=20^{\circ} \mathrm{C}, \mathrm{C}_{0}=200 \mathrm{mg} \mathrm{L}-1\right.$, $\mathrm{pH} 11$ for anionic dyes; $T=5{ }^{\circ} \mathrm{C}, \mathrm{C}_{0}=200 \mathrm{mg} \mathrm{L}^{-1}, \mathrm{pH} 2$ for cationic dyes).

\subsection{Regeneration of exhausted HFC and HFC@CO}

Excellent regeneration capability is a crucial requirement for industrial applications to reduce process costs. Fig. 4 shows that cationic and anionic dyes were efficiently removed from the exhausted HFC and HFC@CO biosorbent during batch adsorption. The adsorption rate decreased slightly with increasing regeneration cycles. The result shows that the removal rate remained above $95 \%$ for anionic dyes and above $90 \%$ for cationic dyes by batch adsorption. Thus, the Huai Flos Chrysanthemum-based material is suitable for the adsorption of dyes and has excellent regeneration capability.

\section{Conclusion}

Raw HFC and HFC@CO were shown to work as effective biosorbents for the removal of anionic and cationic dyes at different temperatures. The best adsorption occurred at $5{ }^{\circ} \mathrm{C}$ and $20{ }^{\circ} \mathrm{C}$, for anionic and cationic dyes, respectively. The equilibrium data were fitted very well to the Langmuir model and a pseudo-second order kinetic model. The thermodynamic parameters indicated that adsorption was a spontaneous exothermic process for anionic dyes and a spontaneous endothermic process for cationic dyes. The excellent performance and regeneration capabilities demonstrate that HFC and HFC@CO are promising biosorbent materials.

\section{Conflicts of interest}

There are no conflicts to declare.

\section{Acknowledgements}

The work was supported by the State Key Laboratory of Water Resource Protection and Utilization in Coal Mining (KFJJ2018052); Youth Science Foundation of Henan Normal University (2017QK22); The PhD established project of Henan Normal University (5101219170125); Key Scientific Project of University in Henan Province (19A610005).

\section{References}

1 S. Shoukat, H. Bhatti, M. Iqbal and S. Noreen, Microporous Mesoporous Mater., 2017, 239, 180-189.

2 Y. Luo, D. Li, L. Bao and J. Zhang, Desalin. Water Treat., 2018, 135, 177-187.

3 S. Dong, X. Ding, T. Guo, X. Yue, X. Han and J. Sun, Chem. Eng. J., 2017, 316, 778-789.

4 Y. Song, T. Li, J. Zhou, F. Pan, B. Su and C. Gao, Desalin. Water Treat., 2016, 57, 17271-17282.

5 J. Liu, Z. Wang, H. Li, C. Hu, P. Raymer and Q. Huang, Bioresour. Technol., 2017, 47, 307-314.

6 Y. Yang, D. Li, C. Li, Y. Liu and K. Jiang, J. Hazard. Mater., 2018, 341, 93-101.

7 L. Tan, C. Yu, M. Wang, S. Zhang, J. Sun, S. Dong and J. Sun, Appl. Surf. Sci., 2019, 467, 286-292.

8 L. Tie, C. Yu, Y. Zhao, H. Chen, S. Yang, J. Sun, S. Dong and J. Sun, J. Alloys Compd., 2018, 769, 83-91.

9 C. Yu, P. Yang, L. Tie, S. Yang, S. Dong, J. Sun and J. Sun, Appl. Surf. Sci., 2018, 455, 8-17.

10 X. Zhang, Z. Lu, D. Ma and Z. Yang, Int. J. Hydrogen Energy, 2015, 40, 346-352. 
11 S. Dong, Y. Cui, Y. Wang, Y. Li, L. Hu, J. Sun and J. Sun, Chem. Eng. J., 2014, 249, 102-110.

12 C. Yu, K. Wang, P. Yang, S. Yang, C. Lu, Y. Song, S. Dong, J. Sun and J. Sun, Appl. Surf. Sci., 2017, 420, 233-242.

13 Y. Li, J. Sun and S. Sun, Chem. Eng. J., 2017, 313, 769-776.

14 X. Han, S. Dong, C. Yu, Y. Wang, K. Yang and J. Sun, J. Alloys Compd., 2016, 685, 997-1007.

15 Y. Tang, J. Zhou, W. Chen, X. Wang and Z. Shen, Integr. Ferroelectr., 2016, 168, 97-106.

16 L. Hu, S. Dong, Q. Li, Y. Li, Y. Pi, M. Liu, X. Han and J. Sun, J. Alloys Compd., 2015, 649, 400-408.

17 L. Hu, S. Dong, Q. Li, J. Feng, Y. Pi, M. Liu, J. Sun and J. Sun, J. Alloys Compd., 2015, 633, 256-264.

18 Q. Wu, Y. Cui, Q. Li and J. Sun, J. Hazard. Mater., 2015, 283, 748-754.

19 A. Kausar, M. Iqbal, A. Javed, K. Aftab, Z. Nazli, H. Bhatti and S. Nouren, J. Mol. Liq., 2018, 256, 395-407.

20 G. Dotto, M. Vieira and L. Pinto, Ind. Eng. Chem. Res., 2012, 51, 6862-6868.

21 A. Mittal, J. Mittal and L. Kurup, J. Hazard. Mater., 2006, 136, 567-578.

22 T. Seey and M. Kassim, International Journal of Applied Science and Technology, 2012, 2, 270-276.

23 R. Gong, Y. Ding, M. Li, C. Yang, H. Liu and Y. Sun, Dyes Pigm., 2005, 64, 187-192.

24 K. Zhu, X. Gong, D. He, B. Li, D. Ji and P. Li, RSC Adv., 2013, 3, 25221-25230.

25 R. Nadeem, Q. Manzoor, M. Iqbal and J. Nisar, J. Ind. Eng. Chem., 2016, 35, 185-194.
26 R. Gong, S. Zhu, D. Zhang, J. Chen, S. Ni and R. Guan, Desalination, 2008, 230, 220-228.

27 J. Ma, Y. Liu, O. Ali, Y. Wei, S. Zhang, Y. Zhang, T. Cai, C. Liu and S. Luo, J. Hazard. Mater., 2017, 344, 1034-1042.

28 M. Mushtaq, H. Bhatti, M. Iqbal and S. Noreen, J. Environ. Manage., 2016, 176, 21-33.

29 K. Mohanty, J. Naidu, B. Meikap and M. Biswas, Ind. Eng. Chem. Res., 2006, 45, 5165-5171.

30 D. Sewu, P. Boakye and S. Woo, Bioresour. Technol., 2017, 224, 206-213.

31 H. Song, H. Zhang, Y. Fu, H. Mo, M. Zhang, J. Chen and P. Li, J. Chromatogr. B: Anal. Technol. Biomed. Life Sci., 2014, 961, 56-61.

32 F. Oliveira, D. Santana, S. Costa, L. Oliveira, V. Liduino and E. Servulo, Waste Manage., 2016, 61, 87-95.

33 Y. Chen, Y. Lin, S. Ho, Y. Zhou and N. Ren, Bioresour. Technol., 2018, 259, 104-110.

34 W. Song, B. Gao, X. Xu, L. Xing, S. Han, P. Duan and R. Jia, Bioresour. Technol., 2016, 210, 123-130.

35 K. Zhu, Y. Duan, F. Wang, P. Gao, H. Jia, C. Ma and C. Wang, Chem. Eng. J., 2017, 311, 236-246.

36 S. Agarwal, I. Tyagi, V. Gupta, M. Dastkhoon, M. Ghaedi, F. Yousefi and A. Asfaram, J. Mol. Liq., 2016, 219, 332-340.

37 Y. Ho and G. McKay, Process Biochem., 1999, 34, 451-465.

38 H. Jia, J. Zhao, X. Fan, K. Dilimulati and C. Wang, Appl. Catal., B, 2012, 123, 43-51.

39 V. Vimonses, S. Lei, B. Jin, C. Chow and C. Saint, Chem. Eng. J., 2009, 148, 354-364.

40 K. Tao, S. Zhao, P. Gao, L. Wang and H. Jia, Ecotoxicol. Environ. Saf., 2018, 161, 237-244. 